\title{
Medical technology: the good and the bad
}

$\mathrm{T}$ oday's physicians still need to possess great clinical skills and knowledge of the human body, but the ability to discern between good and bad medical technologies may be more important now than ever before.

"More and more we read about some cool gizmo that looks like it's going to change the world, but it often never does," says Dr. Matt Strickland, a general surgery resident at the University of Toronto. "Sometimes new technologies are oversold and end up diverting resources from where they should go."

There are a number of questions doctors should ask themselves when evaluating new medical technologies, says Strickland, who presented a talk called "Technology: the good, the bad, the ugly, and you" on Oct. 25 at the International Resident Leadership Summit in Toronto.

\section{Does it actually work?}

"There are a lot of claims made through the tech-press hype cycle, but sometimes the technology literally doesn't work," says Strickland, who is also the cofounder and medical lead for GestSure, a company that created a system that allows surgeons to access digital imagery in operating rooms with hand gestures rather than exiting the sterile environment to use a mouse or keyboard.

\section{How well does it work?}

In health care, unreliable technology just doesn't cut it. A device that fails often has no place in medicine, says Strickland.

\section{How would it work in the clinical environment?}

The technology may have been developed by programmers or hardware designers with great technological skills, but that doesn't mean it will add value in a clinical setting, which has unique time pressures and constraints.

\section{Is it solving a problem that needs to be solved?}

A medical technology might be novel. It might be fun to use. But if doctors can't answer, with great certainty, the question

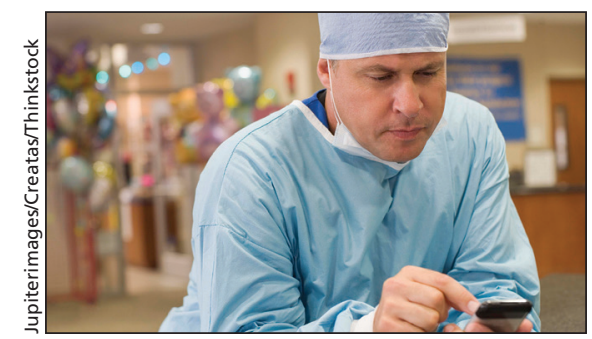

Whether it's a new diagnostic device, app or some other gadget, separating the good from the bad poses challenges.

of whether they see themselves actually using it day to day in their work, that's a red flag, says Strickland.

\section{Will it be around long?}

If the makers of a new medical technology don't have a good track record or a sustainable business plan, their products might not be long for this world. Once the initial hype fades, will the people behind the technology persist or move on to the next big thing? Are there enough users out there to create long-term demand?

\section{Is it trying to do too much?}

A medical tool that is trying to solve too many problems may end up solving none well. Also, many of the functions would likely end up being useless to any given user. "It would be like buying a barbeque with a flashlight," says Strickland.

Despite the challenges of separating the good from the bad, medical residents would be wise to embrace technology, says Strickland. Technical skills can give young physicians a huge advantage in certain environments. For example, it is not uncommon for younger surgeons to be superior operators of laparoscopic surgical devices than their more senior colleagues.

"If you are a young doctor trying to make a name for yourself, as a lot of young residents are, it makes sense to look for opportunities at that edge between health and technology," he says. "Being at that edge gives you an opportunity to accelerate your career." — Roger Collier, CMAJ

CMAJ 2014. DOI:10.1503/cmaj.109-4931 